\title{
What Peer Mentoring Adds to Already Good Patient Care: Implementing the Carpeta Roja Peer Mentoring Program in a Well-Resourced Health Care System
}

Lyndee Knox, $P b D^{1}$

Jessica Huff, MPH, MS

Deborab Grabam, MSPH ${ }^{3}$

Micbelle Henry, MSN, RN ${ }^{4}$

America Bracho, MD, MPH

Cyntbia Henderson, RN, CCM

Caroline Emsermann, $\mathrm{PbD}^{6}$

${ }^{1}$ LA Net Community Health Resource and Research Network, Los Angeles, California

${ }^{2}$ Danbury Hospital Department of Medical Education and Research, Danbury, Connecticut

${ }^{3}$ DARTNet Institute, Aurora, Colorado

${ }^{4}$ WellMed Medical Management, Inc, San Antonio, Texas

${ }^{5}$ Latino Health Access, Santa Ana, California

${ }^{6}$ Department of Family Medicine, University of Colorado School of Medicine, Aurora, Colorado

Conflicts of interest: authors report none.

\section{CORRESPONDING AUTHOR}

Lyndee Knox, PhD

3940-B East Broadway

Long Beach, CA 90803

lyndee.knox@gmail.com

\begin{abstract}
PURPOSE The purpose of this study was to evaluate the impact of a peer support program on the health outcomes of patients already receiving well-organized, comprehensive diabetes care.
\end{abstract}

METHODS We used a mixed-methods, nonrandomized, control-group design to evaluate the impact of a peer-mentoring program on the health outcomes and self-management behaviors of adults with type 2 diabetes in 15 primary care practices in San Antonio. Propensity score analysis, $t$-tests, and multivariable repeated analyses were used to evaluate impact. Qualitative interviews were conducted with 15 participants in the intervention group and analyzed using a grounded theory approach.

RESULTS Both intervention and control groups showed significant improvement on all health indicators from baseline to 6 -month follow-up $(P<.001)$. Hemoglobin $A_{1 c}\left(\mathrm{HbA}_{1 \mathrm{c})}\right.$ decreased slightly faster for patients in the intervention group $(P=.04)$. Self-management behaviors improved significantly from baseline to 6-month follow-up for the intervention group. Interviewed participants also reported reductions in social isolation and extension of impact of health behavior changes to multiple generations of family members.

CONCLUSIONS The addition of peer mentoring to already well-organized comprehensive diabetes care does not improve outcomes. However, findings suggest that the impact of the program extends to members of the participants' families, which is an intriguing finding that deserves further study.

Ann Fam Med 2015;13(Suppl_1):S59-S65. doi: 10.1370/afm.1804.

\section{INTRODUCTION}

P eer mentoring interventions in chronic disease care are intended to help individuals manage their chronic conditions by connecting them with peers from similar life circumstances or with similar health conditions who have been trained to provide social support and education and to share ideas for improving and managing their mentees' health. ${ }^{1-4}$ Research has shown that peer support programs can improve outcomes for patients in low-resource settings..$^{5-9} \mathrm{~A}$ remaining question that few have examined to date is whether or not a peer support intervention program can add to care that is already well resourced and comprehensive.

This study, which set out to answer that question of what peer mentoring adds to already good patient care in the context of diabetes care, took place at WellMed Management group (WMM), which consists of 32 primary care practices serving about 37,000 Medicare-eligible patients. Usual care for diabetes at WMM includes 2 to 4 comprehensive diabetes care visits annually, each including an exam by the patient's primary care provider, a 30-minute session with a health coach, and use of a personal health record. We studied the effect of adding a peer mentoring intervention called Care Companion. 


\section{METHODS}

\section{Care Companion Intervention}

The Care Companion intervention implemented by WMM is modeled after Carpeta Roja, a successful community-based peer mentoring program developed by Latino Health Access in Santa Ana, California. This program has been implemented at Kaiser Permanente and a variety of heath care organizations across the country.

Modifications were made to the Carpeta Roja model to better fit the needs of senior patients at WMM. These included relocation of home visits to the practice to reduce the risk of senior mentors falling when visiting mentees in their homes, shortening workshop sessions to accommodate patient fatigue, and adding a celebration to each group session.

The Care Companion program consisted of 6 elements:

- A series of 8 weekly large-group education sessions called "Diabetes 101."

- Monthly small group mentoring sessions in which participants received continuing education on diabetes self-management and peer support.

- As-needed individual peer-to-peer mentoring sessions at the practice or virtually.

- The use of a paper-based personal health record in addition to the WMM personal health record.

- A comprehensive selection, training, and support program for peer mentors.

- Nurse educator training on how to work effectively with mentors.

The length of the study was fixed, but the duration of services was determined by patient needs and ranged from 4 months to 2 years.

\section{Implementation of the Intervention}

Program staff comprised a program director and diabetes health educators who supported as many as 5 practices each and managed a team of peer mentors recruited from their practices and trained. In addition, a member of the study team (M.H.), the director of preventive care programs at WMM, played a leadership role.

Large- and small-group sessions took place in each practice. Large group sessions included 15 to 20 participants. Small group sessions included 3 to 4 groups of 4 to 5 persons each. Bilingual staff were available to provide sessions in Spanish, but all Spanish-speaking participants indicated that they were comfortable participating in English-language sessions, so all sessions and mentoring encounters were held in English.

Fidelity of the intervention to the Carpeta Roja model was assessed through direct observation by Latino Health Access staff, who conducted 3 site visits to WMM over the course of the study. The program was implemented with a high degree of fidelity. The most significant challenge to implementation was orienting nurse educators to allow peer mentors to lead group sessions. This was addressed by training nurse educators in patient empowerment.

A mixed-methods, nonrandomized study with concurrent controls was used to evaluate the effects of the intervention on patients' health outcomes. A power analysis determined that we would need at least 200 patients in the intervention group. The study was approved by the American Academy of Family Physicians Institutional Review Board.

\section{Practice Selection}

Fifteen WMM primary care practice sites in San Antonio, Texas, had staff and clinicians willing to implement the Care Companion program. Participating practices were located in a variety of settings, including the inner city, suburban communities, and rural areas around San Antonio. Patient populations served by the practices represented a range of income and education levels, as well as a variety of ethnic and racial groups.

\section{Patient Eligibility and Recruitment}

Any patient receiving care from any of the 15 intervention practices who was aged 18 years or older and had a diagnosis of type 2 diabetes with no diagnosis of serious cognitive impairment such as Alzheimer's or another dementia was eligible for inclusion in the intervention group. Intervention group patients received comprehensive WMM diabetes care plus peer support provided through the Care Companions peer mentoring program. Patients were recruited to the intervention group through clinic referral, health coach referral, and self-referral through waiting room posters, mailers, and patient recommendations. A total of 485 patients were enrolled in the intervention group.

Because WMM practices use a common electronic health record, it was possible to include in the usual care group all patients across the 23 practices who met inclusion criteria but did not enroll in the intervention group. A total of 7,879 patients served as controls.

\section{Clinical Data Collection}

Clinical data routinely collected as part of comprehensive diabetes care visits to WMM were used to assess impact of the intervention on clinical outcomes. These were downloaded from the WMM electronic health records (EHR) as described below.

\section{Survey Data Collection and Timeline}

Self-reports of diabetes knowledge and selfmanagement behaviors were collected from intervention group patients using paper surveys. These were administered either in person or by phone by a mem- 
ber of the study team (J.H.). They were collected at the first large-group intervention session, and again at 3 and 6 months after the end of the 8 -week series of large group sessions and follow-up small-group mentoring sessions. In each case, we allowed a 4 -week window following the target dates for collection of survey returns. More information about makeup of the survey instrument is provided in the Measures section, below. These data were not routinely collected as part of patient care and thus are not available for the several thousand patients in the control group.

\section{Qualitative Data Collection}

At the end of the follow-up, 15 intervention participants were selected for key-informant interviews about the impact of the intervention on their health, self-management behaviors, and social networks. A stratified sampling approach was used to select patients from 3 different levels of program participation: low (attendance at 6-8 large group sessions only), moderate (attendance at large group sessions plus individual and small group mentoring), and high (all of the above plus participation in the training to become a peer mentor). In addition, they were selected for their willingness to speak in depth about their experiences and their representation of a range of program experiences from positive to neutral to negative. Nominations were provided by staff from the WMM practices and the Care Companion staff based on these criteria. The key informants were similar in age, ethnicity, sex, and severity of illness to the intervention group as a whole. The purpose of the interviews was to identify unanticipated positive and negative effects of the intervention as well as to gather information for improving the program. Sample size was determined by the research team in order to achieve a saturated model of program effects using grounded theory methods. ${ }^{10}$

\section{Measures}

Demographics

Age and sex were collected from the EHR for both intervention and control participants. Patient race, ethnicity, household income, and education level were collected for the intervention group via the baseline survey.

\section{Clinical indicators}

Data collected as part of routine patient care were used to evaluate impact on biometric variables. Glycated hemoglobin $\left(\mathrm{HbA}_{1 \mathrm{c}}\right)$, low-density lipoprotein $(\mathrm{LDL})$, blood pressure, weight, height, and body mass index (BMI) were abstracted from the EHR over three periods: 0 to 12 months before the intervention for baseline values, and then 0 to 5 months and 6 to 12 months after the end of the large-group sessions (3-month and 6-month follow-up, respectively). Controls drawn from practices without a peer intervention were matched to program participants using propensity score quintiles (described below). Their data-collection periods were synchronized with those of the intervention patients with whom they were matched. Where a patient had multiple visits near these data collection times, data from visit closest to the target date and up to 1 month after the target date were used. The typical interval for comprehensive care visits at WMM ranges from 3 to 6 months depending on patient needs.

\section{Diabetes Knowledge and Self-Management Behavior Survey}

The survey used to assess diabetes knowledge and selfmanagement behaviors included items in the Summary of Diabetes Self-Care Activities, the Behavioral Risk Factor Surveillance System ${ }^{11}$ and the Morisky Scale ${ }^{12}$ for medication adherence..$^{13}$ As explained above, survey data were collected only for the intervention group at baseline (at the first large group session), and at 3 months and 6 months post-intervention.

\section{Key-Informant Interviews}

A 24-item interview guide was developed by the research team at the start of the study. Questions were structured as open-ended queries followed by probes. The interview guide was modified after each interview to incorporate questions about themes and content that emerged during that interview. The interviews were conducted in person, in English, at the practice, and were designed to solicit information about the impact of the program on the patients' health behaviors and health status.

\section{Participation data}

The degree to which intervention patients participated in the large group, small group and peer-to-peer mentoring sessions was assessed from analysis of sign-in sheets and encounter forms.

\section{Analytic Methods for Quantitative Data}

Following customary approaches to selecting variables for propensity matching, we selected a combination of data elements associated with levels of $\mathrm{HbA}_{1 \mathrm{c}}$ control from the literature and clinician expert opinion to arrive at a tentative list, which was reviewed by the entire study team. Variables to include in the final model were chosen by consensus of the team.

Propensity scores were estimated using baseline comorbidities associated with disease severity, including the presence in the patient's EHR record of polyneuropathy, diabetic nephropathy, proliferative or non-proliferative diabetic retinopathy, chronic pulmonary heart disease, cerebrovascular accident, 
aortic calcification, peripheral vascular disease, chronic kidney disease, cirrhosis, congestive heart failure, depression or anxiety, chronic obstructive pulmonary disease, and osteoarthritis, as well as patient sociodemographic characteristics and baseline values of key outcome measures (BMI, systolic blood pressure, LDL, and $\mathrm{HbA}_{1 \mathrm{c}}$ ). Propensity scores were categorized into quintiles for use in analysis of outcomes.

General linear mixed-effects models with random intercepts for patients and practices were used for all primary analyses. These allow for clustering of repeated measures within patients as well as clustering of patients in practices. Multivariable repeatedmeasures mixed models were used to determine whether health indicators improved among patients in the intervention group compared with patients in the comparison group over the 3 data collection points.

Two sets of analyses were conducted, the first comparing the intervention group and the control group, and the second subdividing the intervention group by level of patient participation as described above. All models were adjusted for patient age (centered on the mean), sex, socioeconomic status, quintile categorical propensity, time as a categorical variable, group (peers, non-intervention controls), and a time-by-group interaction. Models were conducted for the outcomes of weight, BMI, LDL, systolic blood pressure, and $\mathrm{HbA}_{1 \mathrm{c}}$.

Before analysis, intervention and control groups were compared on baseline age, sex, $\mathrm{HbA}_{1 \mathrm{c}}$, LDL, blood pressure, and BMI to confirm equivalence. No significant differences were found except in the case of sex. Sixty-two percent of intervention patients were female compared to $55 \%$ of control patients $(P=.005)$.

Self-report surveys from the intervention group members were analyzed for within-group changes from pre- to post-intervention using paired $t$-tests. All analyses were done using SAS 9.3 (SAS Institute, Inc.) and SPSS 19.0 (IBM). Significance of statistical associations was determined with $\alpha=0.05$.

\section{Analytic Methods for Qualitative Data}

We used a grounded theory approach. ${ }^{10}$ Two researchers first analyzed data for content and theme. Then the researchers reviewed their separate codings to develop a third, combined set of content and themes. These were then combined into larger categories and schema describing the effects and underlying mechanisms of the program. The goal of the analysis was to identify a complete continuum of effects on program participants.

Expert member checks of findings were conducted to assess face validity of the findings with $2 \mathrm{WMM}$ program staff, 1 WMM clinician, and 2 WMM patients who participated as mentors in the program. These individuals were selected based on their willingness to participate in this qualitative validation process.

\section{RESULTS}

\section{Study Participants}

A total of 485 patients were enrolled in the intervention group. Clinical data were available for 456 of these participants; survey data were available for all 485. Eighty-two percent of the 485 intervention group members (399) were aged 65 years or older, and $62 \%$ (300) were female. Forty-one percent (197) were Anglo, 45\% (219) were Hispanic, and 7\% (32) were Black. An estimated 33\% of Hispanic patients spoke both English and Spanish. None of the patients who participated were monolingual Spanish or Spanishlanguage preferred. Sixty-eight percent (332) reported 12 or more years of education, $48 \%$ (235) reported household incomes of less than $\$ 25,000$ a year.

\section{Participation Level}

Table 1 shows that $65 \%$ percent of intervention group participants (316) completed 6 or more of the 8 large group sessions only (classified as low-intensity participation). Twenty-four percent (116) completed both the large group sessions and at least 1 peer-topeer mentoring small group session (moderate intensity participation). Eleven percent (53) completed large group sessions and the peer mentoring small group sessions and went on to be trained as peer mentors themselves (high intensity participation). Reasons for dropout from the large group or small group sessions that were reported by WWM program staff on patient attendance/utilization records included deteriorating health, low energy due to age, difficulty finding transportation, and lack of time due to an obligation to provide care for grandchildren.

\section{Clinical Outcomes for Intervention and Control Groups}

Both intervention and control patients showed statistically significant small improvements on all clini-

\section{Table 1. Participation Levels of Intervention Group Members}

\begin{tabular}{lc}
\hline Participation Level & Number (\%) \\
\hline Eligible and enrolled in the intervention & $485(100)$ \\
$\begin{array}{l}\text { Low: Completed } \geq 6 \text { of } 8 \text { large group "Diabetes } \\
\text { 101" education sessions }\end{array}$ & $316(65)$ \\
$\begin{array}{l}\text { Moderate: Also completed } \geq 1 \text { small group session } \\
\text { and individual peer mentor support sessions }\end{array}$ & $116(24)$ \\
$\begin{array}{l}\text { High: Also underwent training to become a peer } \\
\text { mentor }\end{array}$ & $53(11)$ \\
\hline
\end{tabular}


Table 2. Time-by-Group Improvement on Key Health Indicators for Intervention Patients Whose Clinical Data Were available $(n=456)$ vs Controls

\begin{tabular}{|c|c|c|c|c|c|c|c|c|}
\hline \multirow[b]{2}{*}{ Outcome } & \multicolumn{3}{|c|}{ Control } & \multicolumn{3}{|c|}{ Intervention } & \multirow[b]{2}{*}{$\begin{array}{c}P \\
\text { Value } \\
\text { (Time) }\end{array}$} & \multirow[b]{2}{*}{$\begin{array}{l}P \text { Value } \\
\text { (Time- } \\
\text { by- } \\
\text { group) }\end{array}$} \\
\hline & $\begin{array}{l}\text { Baseline } \\
\text { Mean (SE) }\end{array}$ & $\begin{array}{l}\text { 0-5 months } \\
\text { following } \\
\text { 8-week } \\
\text { session } \\
\text { Mean (SE) }\end{array}$ & $\begin{array}{l}\text { 6-10 months } \\
\text { following } \\
\text { 8-week } \\
\text { session } \\
\text { Mean (SE) }\end{array}$ & $\begin{array}{l}\text { Baseline } \\
\text { Mean (SE) }\end{array}$ & $\begin{array}{l}\text { 0-5 months } \\
\text { following } \\
\text { 8-week } \\
\text { session } \\
\text { Mean (SE) }\end{array}$ & $\begin{array}{l}\text { 6-10 months } \\
\text { following } \\
\text { 8-week } \\
\text { session } \\
\text { Mean (SE) }\end{array}$ & & \\
\hline Weight & $171.46(1.07)$ & 170.55 (1.07) & $169.73(1.07)$ & $171.60(2.14)$ & $170.91(2.14)$ & $169.30(2.16)$ & $<.001$ & .40 \\
\hline BMI & $30.53(0.19)$ & $30.37(0.19)$ & $30.24(0.19)$ & $30.45(0.37)$ & $30.32(0.37)$ & $30.04(0.37)$ & $<.001$ & .33 \\
\hline Systolic & $132.38(0.35)$ & $131.31(0.37)$ & $129.93(0.35)$ & $132.24(0.84)$ & $131.18(0.81)$ & $130.4(0.83)$ & $<.001$ & .76 \\
\hline $\mathrm{HbA}_{1 c}$ & $6.22(0.03)$ & $6.19(0.05)$ & $6.15(0.03)$ & $6.35(0.06)$ & $6.22(0.06)$ & $6.13(0.07)$ & $<.001$ & .04 \\
\hline LDL & $98.88(0.78)$ & $95.60(0.83)$ & $95.22(0.85)$ & $98.05(1.59)$ & $97.7(1.95)$ & $95.35(2.03)$ & $<.001$ & .25 \\
\hline
\end{tabular}

$\mathrm{BMI}=$ body mass index; $\mathrm{HBA}_{1 \mathrm{c}}=$ glycated hemoglobin; $\mathrm{LDL}=$ low density lipoprotein.

Note: The table shows repeated measures mixed methods estimates, intervention vs control. Models were adjusted for patient characteristics, propensity, time, patient group, and time by patient group interaction.

cal indicators from baseline to 6-month follow-up (time: $P$ $<.001$ ) (Table 2). Patients in the intervention group experienced slightly more rapid decreases in their $\mathrm{HbA}_{1 \mathrm{c}}$ compared with controls (time-by-group interaction: $P=.04)$. Figure 1 illustrates the difference in rates of decrease between the 2 groups. There were no differences in outcomes by level of participation in the program.

\section{Diabetes Knowledge and} Self-Management Behaviors in the Intervention Group

Participants in the intervention group attained significant improvements in diabetes knowledge. The proportion of the group demonstrating general knowledge about the concept of $\mathrm{HbA}_{1 \mathrm{c}}$ increased from $43.6 \%$ at baseline to $90.1 \%$ at 6 -month follow-up; the proportion who know their own $\mathrm{HbA}_{\mathrm{cc}}$ value also increased from baseline (32.3\%) to 6 -month follow-up $(73.8 \%)$. As Table 3 shows, they also reported significant improvements in selfmanagement behaviors. Specifically, they reported statistically significant increases in the consumption of fruits and vegetables from baseline to 6 -month follow-up $(P<.001)$ and in exercise $(P<.001)$. Significant improvements were
Figure 1. Model estimates of average $\mathrm{HbA}_{1 \mathrm{c}}$ by time and group

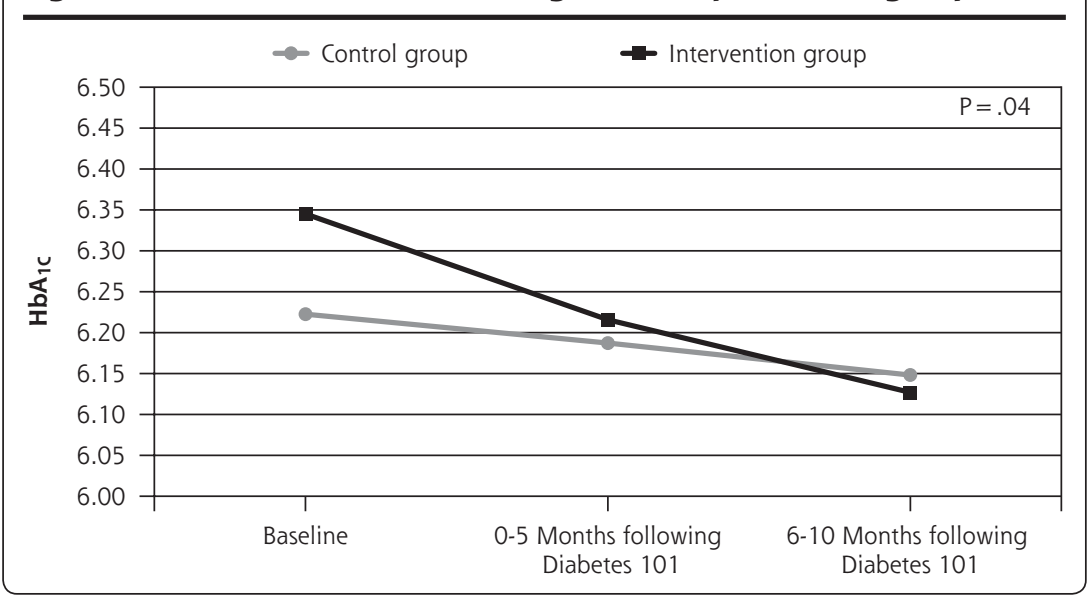

Table 3. Diabetes Self-Management in Intervention Participants

\begin{tabular}{|c|c|c|c|c|}
\hline & $\begin{array}{l}\text { Baseline } \\
(\mathrm{N}=485)\end{array}$ & $\begin{array}{l}3 \text { Mo Post } \\
\text { Intervention } \\
(n=310)\end{array}$ & $\begin{array}{l}6 \text { Mo Post } \\
\text { Intervention } \\
(n=288)\end{array}$ & $\begin{array}{l}P \text { Values } \\
\text { (Baseline } \\
\text { to } 6 \mathrm{Mo} \text { ) }\end{array}$ \\
\hline $\begin{array}{l}\text { Number of days checked } \\
\text { blood sugar in last } 7 \text { days }\end{array}$ & 4.96 & 5.67 & 5.46 & .004 \\
\hline $\begin{array}{l}\text { Number of days ate high } \\
\text { fat intake in last } 7 \text { days }\end{array}$ & 3.16 & 2.63 & 2.62 & .002 \\
\hline $\begin{array}{l}\text { Number of days ate } 5 \text { or } \\
\text { more servings of fruit and } \\
\text { vegetables in last } 7 \text { days }\end{array}$ & 4.18 & 5.06 & 4.99 & $<.001$ \\
\hline $\begin{array}{l}\text { Number of days with } 30 \\
\text { minutes of physical activ- } \\
\text { ity in the last } 7 \text { days }\end{array}$ & 2.54 & 4.02 & 3.28 & $<.001$ \\
\hline $\begin{array}{l}\text { Number of days checkied } \\
\text { feet in last } 7 \text { days }\end{array}$ & 4.97 & 5.61 & 5.51 & .02 \\
\hline $\begin{array}{l}\text { Rating of adherence to dia- } \\
\text { betes medication regimen }\end{array}$ & 0.657 & 0.476 & 0.392 & $<.001$ \\
\hline
\end{tabular}

also found in blood sugar monitoring $(P=.004)$. They also reported improvements in medication adherence 
$(P<.001)$. These outcomes did not vary with intensity of participation.

\section{Key Informant Interviews}

The 15 key informants from the intervention group who were interviewed included 10 females and 5 males aged from 50 years to 75 years. Their reports of improved health outcomes and self-management behaviors were consistent with findings from the data reported above. They also reported increases in social support, reduced feelings of social isolation and increased feelings of hope that they directly attributed to their participation in the peer-mentoring program. These findings did not vary with participation levels of the key informants, but high-participation key informants did report that the program had had a substantial impact on their immediate and extended family members. One respondent reported that her spouse had lost 90 pounds - a weight loss she attributed to her participation in the program. Another reported observing substantial changes in the diet and exercise habits of her adult children and her grandchildren that she attributed to "trickle down" from the program.

\section{DISCUSSION}

Peer mentoring is poised to play an important role in the US healthcare system and in delivering patientcentered care. . $^{1415}$ Thus, understanding the circumstances in which peer mentoring programs are the most effective and when to best implement them is becoming increasingly important. This study of selfselected Medicare participants suggests that adding peer mentoring to comprehensive type 2 diabetes care does not produce substantial improvements in traditional measures of health outcomes for diabetes.

While there was slightly more rapid improvement in $\mathrm{HbA}_{\mathrm{lc}}$ among patients in the intervention group, it is likely that the improvements are of limited clinical significance, especially given the low baseline $\mathrm{HbA}_{\mathrm{lc}}$ values, the majority of patients in both intervention and control groups had well-controlled diabetes going into the study.

Findings from the key-informant interviews suggest that the peer support intervention may have had an effect on the emotional and social well-being of the patients, a finding that is consistent with other research. ${ }^{7,16-20}$ Psychosocial factors are emerging as contributors to both outcomes and cost and are difficult for health care providers to address regardless of the quality of care available. For some key informants, the effects of peer mentoring extended to 2 generations of family members. Since diabetes is a disease that often affects multiple members of a family, the possibility that peer interventions might positively affect the health of multiple members and generations of a family is worthy of additional study.

Limitations to this study include lack of quantitative measures to assess depression and distress associated with diabetes and lack of a comparison group for self-management behavior surveys and for key informant interviews. It is unknown whether control group members participating in WMM's comprehensive diabetes care program also improved their self-care behaviors. Moreover, the assessment of self-care behaviors in the intervention group may have been biased by loss to follow-up. Although propensity adjustment allowed for a valid comparison group, the generalizability of these findings is likely to be limited by the fact that participants were volunteers whose diabetes, blood pressure, and lipids were already well-controlled. Further research should include more robust assessment of impact on emotional distress.

To read or post commentaries in response to this article, see it online at http://www.annfammed.org/content/13/2/Suppl_1/S59.

Key words: diabetes; peer mentoring; peer support

Submitted August 18, 2014; submitted, revised, April 7, 2015; accepted April 20, 2015.

Funding support: Funding for this research was provided by the American Academy of Family Physicians Foundation through the Peers for Progress program with support from the Eli Lilly and Company Foundation.

Previous presentations: Building a Global Network of Peer Support. M. Henry and C. Henderson. San Antonio Health Literacy Collaborative Conference; October, 2009; San Antonio, Texas.

The WellMed Care Companion Program: Empowering Patients to Become Managers of their Own Healthcare. R. Eickhoff, M. Henry, and M. Gomez. Society of Teachers of Family Medicine and American Academy of Family Physicians Conference on Practice Improvement; December 2-5, 2010; San Antonio, Texas.

The WellMed Care Companion Program: Selecting and Training Peer Mentors to Empower Patients. M. Gomez and C. Henderson. Society of Teachers of Family Medicine and American Academy of Family Physicians Conference on Practice Improvement; December 1-4, 2011; Newport Beach, California.

Results of a Peer Mentoring Intervention in Older Patients with Diabetes: The WellMed Care Companion Program. D Graham and C. Henderson. Society of Teachers of Family Medicine and American Academy of Family Physicians Conference on Practice Improvement; November 29-December 2, 2012; Greenville, South Carolina.

High Quality, High Touch Low Cost Care: Lessons from a Patient-Centered Medical Home. W. Pace. American Academy of Family Physicians Scientific Assembly; October 16-20, 2012; Philadelphia, Pennsylvania.

Acknowledgments: We would like to thank Dr Miriam Dickinson for her guidance in the design of this study, Elizabeth Staton for her invaluable editorial expertise, and Dr Wilson Pace for his overall leadership and mentorship. 


\section{REFERENCES}

1. Deakin T, McShane CE, Cade JE, Williams RD. Group based training for self-management strategies in people with type 2 diabetes mellitus. Cochrane Database Syst Rev. 2005;(2):CD003417.

2. Foster G, Taylor SJ, Eldridge SE, Ramsay J, Griffiths CJ. Selfmanagement education programmes by lay leaders for people with chronic conditions. Cochrane Database Syst Rev. 2007;(4):CD005108.

3. World Health Organization. Peer Support Program in Diabetes: Report of a WHO Consultation, November 5-7, 2007. Geneva, Switzerland: World Health Organization; 2008.

4. Dale JR, Williams SM, Bowyer V. What is the effect of peer support on diabetes outcomes in adults? A systematic review. Diabet Med. 2012;29(11):1361-1377.

5. Fisher EB, Boothroyd RI, Coufal MM, et al. Peer support for selfmanagement of diabetes improved outcomes in international settings. Health Aff (Millwood). 2012;31(1):130-139.

6. McEwen MM, Pasvogel A, Gallegos G, Barrera L. Type 2 diabetes self-management social support intervention at the U.S.-Mexico border. Public Health Nurs. 2010;27(4):310-319.

7. Shaya FT, Chirikov VV, Howard D, et al. Effect of social networks intervention in type 2 diabetes: a partial randomised study. J Epidemiol Community Health. 2014;68(4):326-332.

8. Eisen SV, Schultz MR, Mueller LN, et al. Outcome of a randomized study of a mental health peer education and support group in the VA. Psychiatr Serv. 2012;63(12):1243-1246.

9. Cook JA. Peer-delivered wellness recovery services: from evidence to widespread implementation. Psychiatr Rehabil J. 2011;35(2):87-89.

10. Strauss A, Corbin B. Basics of Qualitative Research: Grounded Theory Procedures and Techniques. Los Angeles, CA:Sage Publications; 2014.
11. Centers for Disease Control and Prevention. Behavioral Risk Factor Surveillance System. 2014. http://www.cdc.gov/brfss/.

12. Toobert DJ, Hampson SE, Glasgow RE. The summary of diabetes self-care activities measure: results from 7 studies and a revised scale. Diabetes Care. 2000;23(7):943-950.

13. Morisky DE, Green LW, Levine DM. Concurrent and predictive validity of a self-reported measure of medication adherence. Med Care. 1986;24(1):67-74.

14. Piette JD, Holtz B, Beard AJ, et al. Improving chronic illness care for veterans within the framework of the patient-centered medical home: experiences from the Ann Arbor Patient-Aligned Care Team Laboratory. Trans/ Behav Med. 2011;1(4):615-623.

15. Petterson SM, Liaw WR, Phillips RL Jr, Rabin DL, Meyers DS, Bazemore AW. Projecting US primary care physician workforce needs: 2010-2025. Ann Fam Med. 2012;10(6):503-509.

16. van Dooren FE, Nefs G, Schram MT, Verhey FR, Denollet J, Pouwer F. Depression and risk of mortality in people with diabetes mellitus: a systematic review and meta-analysis. PLoS One. 2013;8(3):e57058.

17. Pfeiffer PN, Heisler M, Piette JD, Rogers MA, Valenstein M. Efficacy of peer support interventions for depression: a meta-analysis. Gen Hosp Psychiatry. 2011;33(1):29-36.

18. Pantell M, Rehkopf D, Jutte D, Syme SL, Balmes J, Adler N. Social isolation: a predictor of mortality comparable to traditional clinical risk factors. Am J Public Health. 2013;103(11):2056-2062.

19. Coyle CE, Dugan E. Social isolation, loneliness and health among older adults. J Aging Health. 2012;24(8):1346-1363.

20. Solomon P. Peer support/peer provided services underlying processes, benefits, and critical ingredients. Psychiatr Rehabil J. 2004;27(4):392-401. 